
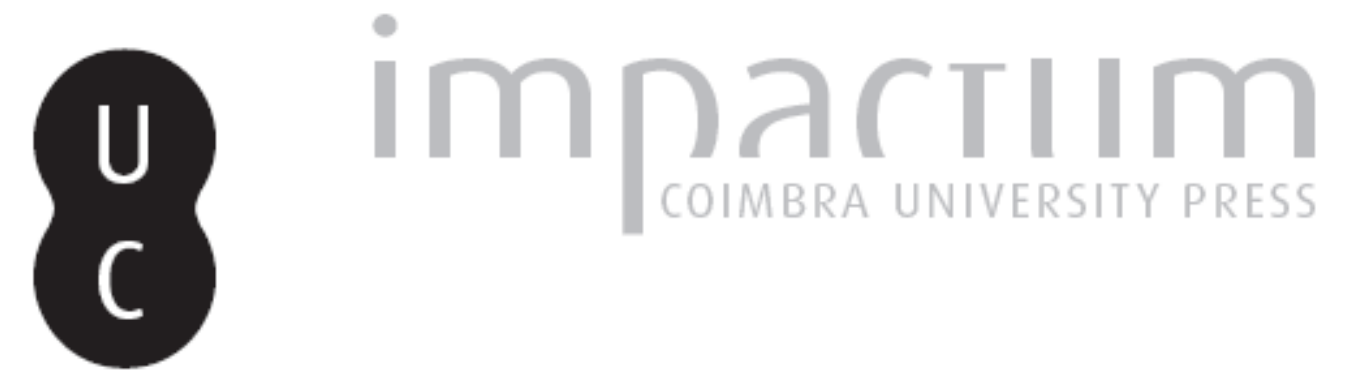

\title{
Rumo à Sociedade Mundial do Gênero Humano?
}

\section{Autor(es): $\quad$ Comparato, Fábio Konder}

Publicado por: Faculdade de Direito da Universidade de Coimbra

URL persistente:

URI:http://hdl.handle.net/10316.2/24742

DOI:

http://dx.doi.org/10.14195/0870-4260_51_2

Accessed : $\quad$ 26-Apr-2023 15:07:46

A navegação consulta e descarregamento dos títulos inseridos nas Bibliotecas Digitais UC Digitalis, UC Pombalina e UC Impactum, pressupõem a aceitação plena e sem reservas dos Termos e Condições de Uso destas Bibliotecas Digitais, disponíveis em https://digitalis.uc.pt/pt-pt/termos.

Conforme exposto nos referidos Termos e Condições de Uso, o descarregamento de títulos de acesso restrito requer uma licença válida de autorização devendo o utilizador aceder ao(s) documento(s) a partir de um endereço de IP da instituição detentora da supramencionada licença.

Ao utilizador é apenas permitido o descarregamento para uso pessoal, pelo que o emprego do(s) título(s) descarregado(s) para outro fim, designadamente comercial, carece de autorização do respetivo autor ou editor da obra.

Na medida em que todas as obras da UC Digitalis se encontram protegidas pelo Código do Direito de Autor e Direitos Conexos e demais legislação aplicável, toda a cópia, parcial ou total, deste documento, nos casos em que é legalmente admitida, deverá conter ou fazer-se acompanhar por este aviso.

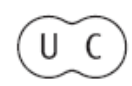




\section{UNIVERSIDADE DE COIMBRA \\ FACULDADE DE DIREITO}

BOLETIII DE CÊACCLS ECONÓNCACAS

VOLUME LI

$\begin{array}{llll}2 & 0 & 0 & 8\end{array}$

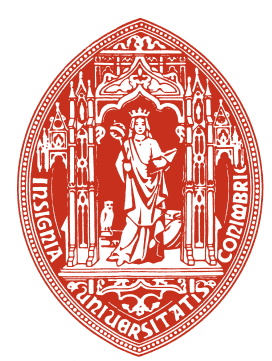

COIMBRA 


\section{RUMO \\ À SOCIEDADE MUNDIAL DO GÊNERO HUMANO?}

Quem observa, ainda que de modo rápido e superficial, as últimas cinco centúrias da vida humana no planeta - ou seja, grosso modo, o tempo histórico decorrido desde a descoberta do continente americano pelos europeus -, não pode deixar de perceber o fenômeno da rápida intensificação das relações entre todos os povos do mundo.

O ponto de partida desse movimento de coalescência espacial do gênero humano na face da Terra é, claramente, o final do século XV. Até então coexistiam, sem se integrarem, várias civilizações, isto é, reuniões de povos que falavam línguas da mesma família, partilhavam dos mesmos valores e das mesmas tradições, sobretudo religiosas, possuíam as mesmas instituições sociais e dispunham dos mesmos conhecimentos técnicos. Cada um desses arquipélagos humanos considerava-se o centro do universo e via, portanto, com desconfiança e desprezo todos os demais.

Em pouco mais de cem anos, entre 1405 - quando o almirante chinês Zhen Hê realizou a primeira de sete expedições transoceânicas entre a China e a costa oriental da África - e 1522, ano em que o último navio sobrevivente da esquadra de Fernão de Magalhães completou a primeira viagem de circunavegação do globo terrestre, todas as civili- 
zações passaram a viver, simultaneamente, em contato permanente umas com as outras.

$\mathrm{Na}$ realização dessa estupenda façanha, a gente portuguesa teve, como sabido, participação decisiva. Uma nação de menos de um milhão e meio de habitantes desafiou a tradição dogmática e provou, com um "saber só de experiências feito", a verdade simples de que a Terra é redonda. Deu com isto "novos mundos ao mundo" (II, 360), como cantou Camões; e "se mais mundo houvera, lá chegara" (VII, 112).

Sem dúvida, o simples adensamento demográfico na superfície esférica do planeta conduziria, necessariamente, a esse resultado. Faltava, porém, dar um sentido de organização ao todo assim criado.

Esse sentido foi dado, não mais pelo ímpeto aventureiro de um punhado de navegantes, mas no quadro frio e racional do primeiro movimento essencialmente moderno que o mundo conheceu - isto é, sem pátria, sem tradições e sem religião: o capitalismo.

Duas transformações técnicas decisivas, engendradas pelo sistema capitalista, marcaram a rápida aproximação mundial dos povos. A primeira, iniciada em meados do século XVIII, foi a agilização dos meios de transporte por terra, mar e ar. A segunda, a partir do século seguinte, com o telégrafo sem fio, prosseguiu com o telefone, o cinema, o rádio e a televisão, e culminou com a invenção da informática e da internet na segunda metade do século passado. Doravante, o globo terrestre passou a ser recoberto de uma rede cada vez mais densa de meios de telecomunicação, sem deslocamento físico das pessoas.

$\mathrm{Na}$ lógica própria do capitalismo, o objetivo final de ambas essas revoluções industriais foi a constituição de um mercado mundial unificado. Instaurou-se, com ele, a homogeneização cosmopolita, não apenas da vida econômica compreendendo os modos de produção, de distribuição de 
bens e dos hábitos de consumo -, mas também do enorme complexo dos costumes, valores e expressões culturais, que desde sempre demarcaram as fronteiras de cada civilização. Uma uniforme sociedade de massas assentou-se nos quatro cantos do mundo.

Nesse avanço triunfal ao redor da Terra, o capitalismo só encontrou um adversário de peso: o comunismo. Mas o embate entre ambos não durou nem três quartos de século. O Manifesto de 1848 nunca foi tão profético, em termos reais e simbólicos, quanto ao anunciar que "o preço reduzido de suas mercadorias é a grossa artilharia com que a burguesia demole todas as muralhas da China".

Os grandes agentes do novo mercado mundial unificado são as empresas ditas multinacionais ou transnacionais. As primeiras instalam-se em diversos países e submetem-se à legislação local. As transnacionais, diferentemente, operam no mundo todo, não mediante investimentos locais, mas por meio da criação de uma rede contratual de fornecedores, programadores, montadores e distribuidores. Calcula-se, hoje, que o volume total de negócios das 150 maiores empresas multinacionais e transnacionais supera o PIB de 150 países, e equivale a quase 30\% do produto mundial.

Que dizer desse fenômeno sem precedentes na História? Teremos feito da Terra uma verdadeira oikoumene, como se dizia na língua de Homero, isto é, a casa comum do gênero humano? Chegamos, afinal, ao preâmbulo daquela communis humani generis societas, anunciada por Cícero há mais de vinte séculos?

Certamente não. A nenhum observador perspicaz passa despercebido que vivemos, neste dealbar do novo milênio, um autêntico momento de crise. Importa, porém, devido ao abuso do vocábulo na linguagem corrente, explicar desde logo o sentido que lhe é aqui atribuído. 
O substantivo krisis, cognato do verbo krineo, que no grego clássico tinha duas acepções básicas - joeirar ou separar; discernir ou julgar -, assumiu na linguagem própria de Hipócrates a conotação especial de mudança súbita, desequilíbrio ou ruptura.

No tratado Dos Ares, das Águas e dos Lugares, o Pai da Medicina denominou krisis o momento preciso em que é possível discernir a doença e desvendar a sorte do doente. É o instante em que o olhar experiente do médico observa uma mudança súbita no estado do paciente, para o bem ou para o mal; o momento em que se declaram nitidamente os sintomas da moléstia, permitindo o diagnóstico e o prognóstico.

Ora, alguns sintomas graves parecem anunciar, atualmente, a desagregação do sistema de mercado mundial instaurado pelo capitalismo.

O primeiro deles é a fratura da humanidade em duas partes, que se destacam sempre mais uma da outra: a minoria opulenta e a maioria indigente. Em 1960, os 20\% mais ricos da população mundial dispunham de uma renda média 30 vezes superior à dos 20\% mais pobres. Em 1997, essa proporção havia mais do que dobrado: 74 para 1 . No início do atual século, ela passou a ser de 80 para 1.

O aspecto eticamente mais grave, nesse cenário, é que são os países pobres que financiam os ricos e não o contrário. Segundo dados do FMI, divulgados em recente estudo das Nações Unidas, o volume líquido da transferência de recursos financeiros dos países subdesenvolvidos aos desenvolvidos, que era nulo em 1995, atingiu US\$760 bilhões em 2007.*

$\mathrm{Na}$ origem dessa espécie de deriva social dos continentes encontra-se, justamente, a expansão do sistema capitalista

${ }^{\star}$ World Economic Situation and Prospects 2008, 69 ss. 
ao mundo todo, a partir da sua matriz européia. Até o século XIX, como mostraram os estudos de Angus Madison, quase dois terços da produção mundial eram gerados no continente asiático, sendo a Europa Ocidental e a América do Norte responsáveis por menos de um terço do todo. Desde então, porém, ao fazer dos demais continentes a extensão do seu próprio mercado, o capitalismo europeu neles provocou a destruição, não só das formas de produção tradicionais, como também da própria organização social.

A segunda fase da globalização capitalista, na qual vivemos, apresenta nítidos sinais de exaustão. A entropia, ou perda de energia do sistema, origina-se sempre de um excesso de capacidade de produção instalada, em relação à curva declinante do consumo, a longo prazo. Daí o esforço contínuo na criação de necessidades artificiais de bens e serviços, pelo recurso intensivo à propaganda comercial.

Ora, a partir de 1998, os gastos publicitários no mundo aumentam, ano a ano, em ritmo maior do que o crescimento da produção mundial. Pior: atualmente, o ritmo de expansão das despesas empresariais com publicidade e propaganda é incomparavelmente maior nos países pobres do que nos ricos. Assim, entre 2003 e 2007, a expansão foi de 18,2\% na África e no Oriente Médio, contra 4,9\% na América do Norte e 3,9\% na Europa.

Por outro lado, verifica-se hoje, no mundo todo, a predominância das cadeias de distribuição sobre os centros produtivos; vale dizer, a empresa distribuidora de bens, ou intermediária de serviços, sobrepuja a industrial. A maior empresa do mundo, hoje, não é do setor petrolífero nem do automotivo. É a Wal-Mart, que explora supermercados.

A par dessas fraquezas internas, o capitalismo industrial vem sofrendo, desde o último quartel do século passado, o impacto devastador da febre especulativa e usurária, que tomou conta do mercado mundial. As tradicionais virtudes 
puritanas de poupança obrigatória, de repúdio a toda forma de luxo (equiparado à luxúria), e de dedicação intensiva ao trabalho, as quais formavam no dizer de Max Weber o "espírito" do capitalismo, tinham por objetivo a formação de um sólido capital, sem aventuras e riscos excessivos. Hoje, tais virtudes modelares acham-se sufocadas pela busca do ganho fácil e imediato.

O resultado é que, um pouco em toda parte, as empresas industriais procuram valorizar artificialmente suas ações em Bolsa, não só pela farta distribuição de dividendos, mas também mediante operações de resgate e compra de suas próprias ações, assim como pela emissão maciça de opções de compra (stock options), distribuídas generosamente aos administradores. Para tanto, é obviamente necessário aumentar ao máximo os ativos líquidos e abandonar os programas de investimento.

As fusões e incorporações empresariais, que se multiplicam nos dias atuais, inserem-se na mesma linha estratégica. Não se trata de aumentar a capacidade de investimento, mas de dominar o mercado e reduzir os custos, sobretudo com o pessoal assalariado (down-sizing).

Tudo isto sucede num momento em que o capitalismo financeiro conhece uma perigosa deriva, do financiamento tradicional à pura e simples especulação. As instituições financeiras já por si nada produzem; são meras auxiliares na produção. Portanto, subordinar o setor industrial ao financeiro representa uma aberração: é pôr o carro adiante dos bois. Ora, com o jogo e a aposta transformados em atividade empresarial, nem mesmo esse semblante de auxílio à produção é preservado.

Tomemos os fundos de hedge, destinados a especular com quaisquer bens ou valores, materiais ou imateriais, desde commodities, até moedas nacionais, selos ou jogadores de futebol. O empresário português Nuno Gonçalves, por 
exemplo, criou três fundos de hedging, no montante inicial de 14 milhões de dólares, para especular sobre as altas e baixas no valor da transferência dos grandes astros do futebol internacional de um clube para outro. A característica própria desses fundos é que o capital de empréstimo supera o volume de recursos próprios. Estabelece-se, assim, a vinculação entre o crédito bancário e o jogo, que o mundo clássico dos negócios sempre considerou anátema.

Segundo estudo recente, levado a efeito pelo McKinsey Global Institute, o total dos ativos financeiros em circulação no mundo vem aumentando mais rapidamente do que a produção mundial. No início do decênio de 80 do século passado, as cifras eram quase iguais: US $\$ 10$ trilhões de produção, para US $\$ 12$ trilhões de ativos financeiros. Em 2006, enquanto o total da produção mundial elevava-se a pouco mais de US\$48 trilhões, o montante global dos ativos financeiros atingia a fabulosa cifra de US\$167 trilhões; ou seja, mais do que o triplo.

Em princípio, o valor de mercado desses títulos tem como lastro o valor real de bens e serviços originariamente produzidos ou prestados, que tais contas ou papéis representam, diretamente ou por superposição de aplicações. Há, porém, situações em que nem mesmo esse lastro material existe, como sucede nos fundos de hedge, ou nas operações sobre índices futuros ou derivativos, que têm por objeto a variação da taxa de juros, do câmbio de moedas, ou do preço das commodities, no mercado nacional ou internacional.

Não é, portanto, de se excluir que um súbito calafrio de desconfiança, a percorrer o corpo global dos aplicadores e distribuidores no mercado de capitais, transforme-se em pânico febril, provocando em poucas horas o esfacelamento de todo esse edifício de créditos e papéis financeiros, como um castelo de cartas. 
Se esse clima de insegurança generalizada instalou-se no mercado globalizado, a humanidade vê-se também, no presente, às voltas com o recrudescimento de um flagelo que a acompanha ao longo de toda a História: a guerra.

Há países, como a Colômbia, e regiões inteiras, como o Oriente Médio, que permanecem em estado de ininterrupta beligerância há mais de meio século.

Segundo o Relatório do Desenvolvimento Humano das Nações Unidas de 2000, no último quartel do século XX uma verdadeira pandemia de guerras civis, massacres e genocídios exterminou cerca de 5 milhões de pessoas.

A conseqüência inevitável desse descontrole bélico é o incremento considerável do número de refugiados. O Alto Comissariado das Nações Unidas para os Refugiados, hoje sob a chefia de um antigo primeiro-ministro de Portugal, António Guterres, estima que existem no mundo $33 \mathrm{mi}-$ lhões de pessoas nessas condições.

Acresça-se a esse estado de beligerância globalizada o ressurgimento do terrorismo, sem identidade nacional nem domicílio fixo, alimentado amiúde pelo fanatismo religioso, e levantando agora, sinistramente, a ameaça de utilização de engenhos nucleares portáveis, para se compreender o temor que se instala em estado larvar no mundo inteiro.

Em 1945, com o lançamento das primeiras bombas atômicas no Japão, a humanidade enxergou a sombra do Apocalipse, ao se dar conta, subitamente, da possibilidade de um suicídio coletivo.

Agora, na abertura deste novo milênio, um temor menos agudo, mas de natureza mais profunda e implacável, pelo grau de sua previsibilidade científica, toma conta das mentes: a destruição da biosfera. Como nos adverte o Relatório de Desenvolvimento Humano referente a 2007/ 12008, das Nações Unidas, contamos com um lapso de tempo diminuto - 10 a 15 anos - para estabilizar em nível 
mundial o volume de emissões de gases-estufa e começar a reduzi-lo, antes que se desencadeie uma catástrofe de efeitos irreversíveis.

É bem o caso de dizer que, nesse novo cenário, como anunciado no belo poema de T. S. Eliot (The Hollow Men), o fim do mundo não se abaterá sobre nós com um estrondo, mas com uma lamúria ("not with a bang, but with a whimper").

Que dizer disso tudo? A única espécie de seres vivos que foi capaz de passar da condição de objeto à de sujeito dirigente do processo evolutivo haverá de interromper sua existência miseravelmente, num lamentável prolapso? Seremos, afinal, meros joguetes nas mãos da divindade, como acreditavam os antigos, ou sujeitos passivos dos determinismos fisico-químicos, como sustentam alguns cientistas?

Felizmente, não é dificil perceber que, ao lado da globalização disruptiva, produzida pelo capitalismo, está em curso, nos três últimos séculos, um amplo movimento de mundialização associativa e comunitária.

A convicção profunda de que os homens - e, por conseguinte, os povos - são essencialmente iguais, em sua radical dignidade, é o sólido fundamento sobre o qual vai sendo construído, andar por andar, o edifício do sistema universal dos direitos humanos. Sucessivamente, foram reconhecidos como titulares desses direitos os indivíduos, os grupos sociais mais carentes, os povos e agora, finalmente, a humanidade como um todo.

A confrontação agônica entre esses dois movimentos holísticos - a globalização capitalista e a mundialização humanista - está no centro da crise atual. Qual o seu desfecho?

Em ensaio publicado em 1931 (Die gestige Situation der Zeit), Karl Jaspers distinguiu com acuidade dois tipos de previsão histórica: a simplesmente especulativa (dachtende Prognose) e a instigante (erweckende Prognose). A primeira é 
um puro exercício intelectual. O observador imagina-se fora do mundo, como espectador do "teatro da História". A segunda, ao contrário, faz-se não apenas com o intelecto, mas também com a vontade, a sensibilidade valorativa e o juízo ético. Neste sentido, ela é instigante da ação, pois supõe em cada um de nós a consciência de que somos sempre, respeitadas certas condições, senhores do nosso próprio destino.

Ao contrário dos animais gregários, cuja reunião em bandos é dirigida pelo puro instinto, a subsistência da espécie humana depende da organização de sociedades. Não se trata de um fenômeno natural, mas, bem ao contrário, do resultado de um ato de vontade dirigido a um objetivo determinado, o qual pode ou não ser alcançado. Foi exatamente nesse sentido que Aristóteles definiu o ser humano como um animal político.

As desconexões e turbulências em escala planetária, há pouco assinaladas, demonstram a imperiosa necessidade de se constituir, sem maiores tergiversações, uma organização política mundial capaz de proteger a humanidade contra o risco de desagregação, ou mesmo de desaparecimento, por efeito, quando mais não seja, da progressiva destruição do meio ambiente.

Para a consecução desse objetivo maior, desnecessário dizer que o ideário e os instrumentos institucionais do sistema capitalista se revelam totalmente inadequados. "É evidente", advertiu Aristóteles há vinte e quatro séculos (Política 1280 b, 25-30), "que a pólis não é, meramente, a coabitação de pessoas no mesmo território, a fim de que os cidadãos gozem de segurança e mantenham boas relações de negócio". A verdadeira sociedade política, lembrou ele com insistência, é uma comunhão (koinonia), onde o bem comum do povo - que os romanos denominaram res publica - não pode jamais subordinar-se ao interesse particular de indivíduos ou grupos. 
No plano internacional, tal significa, na feliz expressão de Camões, estabelecer "na paz, leis iguais, constantes, que aos grandes não dêem o dos pequenos" (IX, 745-746).

À luz desse imperativo categórico, somos todos convocados a colaborar na construção da sociedade mundial do gênero humano, segundo os atuais padrões de legitimidade política, aceitos pela consciência ética. Eles correspondem aos princípios fundamentais da república e da democracia. O primeiro diz respeito à finalidade do exercício do poder; o segundo, à sua titularidade.

Reunir todos os povos da Terra numa sociedade republicana significa sobrepor o bem comum da humanidade ao interesse próprio de cada um deles e, com maioria de razão, à vantagem particular de empresas ou grupos de qualquer espécie. Daí decorrem algumas exigências básicas.

A primeira delas é o reconhecimento do caráter público e, por conseguinte, inapropriável por Estados ou empresas privadas, dos bens necessários à sobrevivência de todos os seres humanos em condição de mínima dignidade.

Nesse sentido, o direito internacional hodierno já declara como patrimônio da humanidade certos bens de valor histórico, artístico ou paisagístico (Convenção da Unesco de 1972), bem como o leito do mar, os fundos marinhos e seu subsolo, além dos limites da jurisdição nacional (Convenção do Direito do Mar de 1982).

A esses bens inapropriáveis hão de acrescentar-se, necessariamente, os grandes conjuntos florestais e as reservas naturais de água potável, no mundo todo. Os países onde eles se situam têm o dever de geri-los e preservá-los em prol da humanidade. Não pode haver, nessa matéria, soberania nacional.

A segunda exigência republicana fundamental consiste em instaurar um regime de aproveitamento comunitário para o conjunto das invenções técnicas. Já no início do 
mundo moderno, Rabelais lançava a advertência famosa: science sans conscience n'est que ruine de l'âme. Da mesma sorte, podemos e devemos hoje proclamar que o desenvolvimento técnico ilimitado, sem a necessária regulação ética, conduz à ruína da humanidade.

Os empresários capitalistas foram os primeiros na História a compreender a importância do saber tecnológico para o desenvolvimento da atividade econômica. Hoje, ao contrário do que pensaram os economistas clássicos e o próprio Karl Marx, a tecnologia é incontestavelmente o principal fator de produção, muito acima da força-trabalho e dos bens materiais. Daí o fortalecimento generalizado da propriedade intelectual.

Ora, apropriar-se do saber tecnológico como instrumento para a obtenção de lucros significa, em muitos casos, condenar ao atraso e à sujeição a maioria esmagadora da população mundial.

É o que ocorre, de modo paradigmático, no campo da indústria farmacêutica. Relatório recente de uma das mais respeitadas organizações não governamentais do planeta revela que das 163 fórmulas medicamentosas patenteadas no mundo, entre 1999 e 2004, apenas 3 visam ao tratamento de doenças tropicais. E a razão é óbvia: os povos pobres não dispõem de recursos para comprar remédios patenteados, pois os preços de venda são fixados em níveis muito elevados, a fim de permitir aos fabricantes a amortização em curto prazo dos custos de pesquisa e investimento, incorridos na invenção desses medicamentos.

Põe-se, aí, a necessidade incontornável de se criarem, nos diferentes Estados e no seio de organizações internacionais, fundos públicos destinados a financiar os trabalhos de pesquisa científica e tecnológica de criação de medicamentos, a serem distribuídos no mercado pelo menor preço possível. 
Se essas, entre outras, são as exigências básicas da organização republicana da sociedade mundial, como garantir que o poder político seja exercido em prol do bem comum da humanidade, e não no interesse próprio dos Estados mais poderosos e da fração populacional mais rica do planeta?

Entramos, aí, na discussão da titularidade do poder político mundial a ser criado.

No presente, como ninguém ignora, o regime democrático é reconhecido como o único legítimo, ainda que a democracia oficial esteja longe de corresponder à democracia real.

A razão desse descompasso entre a forma e o fundo é, incontestavelmente, de ordem semântica. A democracia, desde sempre, tem sido definida como o regime político em que o povo é soberano. Mas o que é soberania? Se aceitarmos a opinião largamente difundida de que ela coincide com o direito de eleger os governantes, compreenderemos, sem grande esforço de análise, por que razão raríssimos povos no mundo de hoje se consideram efetivamente soberanos. Em pesquisa recente de âmbito mundial, realizada por conceituado instituto de opinião pública, verificou-se que não mais do que $8 \%$ dos entrevistados confiavam em seus respectivos representantes políticos.

Já é tempo de se desmistificar a teoria da representação popular, forjada ao longo do século XIX, como arma de combate da burguesia montante contra o poder aristocrático tradicional. A soberania política não se reduz ao simples direito de eleger os governantes, mas corresponde, antes, àquilo que a técnica jurídica empresarial denomina poder de controlo. No campo político, ele consiste na competência inalienável de aprovar diretamente a Constituição da pólis e suas modificações ulteriores, de fixar, em qualquer tempo, as grandes diretrizes de governo, de exigir dos governantes eleitos o rigoroso cumprimento dessas diretrizes, bem como de destituí-los em caso de perda de confiança (recall). 
Sob esse aspecto, no quadro das relações internacionais, devem ser reconhecidos como soberanos, não os Estados, mas os povos.

É essa a primeira etapa no processo de constituição de uma sociedade política mundial, processo esse que obedecerá, necessariamente, ao esquema federativo, comportando três esferas políticas integradas: a local (correspondente aos Estados atuais), a regional e a mundial. A organização política regional pode adotar um modelo mais ou menos integrado, competindo aos seus membros decidir se continuarão a agir de modo autônomo, ou se a união cria, em seu relacionamento externo, uma única unidade política de estrutura confederativa.

Escusa ressaltar que, na constituição de cada uma dessas esferas políticas integradas, o princípio democrático exige que a vontade constituinte seja dos povos e só deles. Eis porque foi lamentável a decisão dos Estados integrantes da União Européia de aprovar o recente Tratado de Lisboa mediante simples acordo diplomático e não por meio de referendos populares nacionais.

O fecho de abóbada, na organização da sociedade política mundial, há de ser constituído pela atual Organização das Nações Unidas. Ninguém ignora que a sua sobrevivência encontra-se atualmente ameaçada pela concentração do poder oligárquico nas grandes potências internacionais. Os Estados Unidos, em particular, que foram os grandes inspiradores da criação da ONU ao final do segundo conflito mundial, movem contra ela, no presente, uma guerra sem quartel. Daí a importância e a urgência de se encetar uma reforma das Nações Unidas.

Tal como nas outras esferas políticas, ela deve fazer-se em obediência ao princípio democrático, isto é, no nível da soberania e dos órgãos de governo.

Quanto à soberania, o pressuposto fundamental para que um Estado (ou federação de Estados) seja membro da 
ONU é que ele tenha, efetivamente e não apenas em aparência, uma estrutura democrática; isto é, que os seus órgãos de poder sejam representativos do povo, livre e soberano, e responsáveis perante ele.

Em matéria de órgãos de governo das Nações Unidas, é imprescindível reconhecer que os integrantes do Conselho de Segurança devam ser todos eleitos periodicamente pela Assembléia Geral, e que nenhum deles disponha do poder de veto. Importa, ainda, criar sanções adequadas para garantir a observância das decisões desse órgão. Nesse sentido, já tive ocasião de sugerir a instituição da pena de suspensão automática do direito de voto do Estado-membro inadimplente, em todos os órgãos das Nações Unidas, suspensão essa que perduraria até que ele viesse a cumprir seu dever associativo.

$\mathrm{Na}$ Assembléia Geral, admitido o princípio da representatividade democrática, é insustentável manter em vigor a atual regra da igualdade de votos de todos os Estados. O peso demográfico não pode deixar de ser levado em conta na regulação do sufrágio, como acaba de ser instituído pelo Tratado de Lisboa no seio do Conselho Europeu.

Ainda quanto à Assembléia Geral das Nações Unidas, as suas resoluções normativas devem entrar em vigor desde logo com a sua aprovação, e não apenas servir de matéria à adoção posterior de tratados internacionais entre os seus membros.

A tarefa de construção de uma democracia mundial completar-se-á, necessariamente, com a organização de um Poder Judiciário forte e autônomo. Nesse sentido, é indispensável abolir a cláusula de reconhecimento facultativo da jurisdição da Corte Internacional de Justiça, nos moldes do disposto no Protocolo n. ${ }^{\circ} 11$ à Convenção Européia de Direitos Humanos, no tocante ao Tribunal de Estrasburgo. A nenhum membro das Nações Unidas deve ser lícito 
subtrair-se à jurisdição da Corte, de modo a sobrepor o seu interesse próprio à realização da justiça no plano internacional.

Ainda no concernente às funções judiciárias, no seio das Nações Unidas, é indispensável criar um tribunal internacional, com ampla competência para conhecer e julgar os casos de violação de direitos humanos pelos Estados-membros, a exemplo das Cortes, Européia e Americana, de Direitos Humanos.

Eis aí, em largos traços, o que me parece deva ser o programa mínimo de regeneração da humanidade, na crise profunda em que se acha metida, neste início do segundo milênio da era cristã.

Não basta, porém, nessa matéria, pensar em soluções, sem cuidar de aplicá-las. Ao concluir a sua Ética a Nicômaco (1179 b, 1-3), Aristóteles relembra que o objetivo, nas ciências práticas, não é simplesmente contemplar e pensar (theoressai kai gnonai) a realidade, mas transformar a teoria em ações concretas.

Eis porque, usufruindo do honroso privilégio de falar, como alguém da Casa, na mais antiga e prestigiosa Universidade de língua portuguesa, ouso propor que, daqui mesmo, levante-se um movimento em prol da constituição de uma sociedade comunitária do gênero humano; movimento para o qual devem ser convidados todos os homens e mulheres de boa vontade, nos quatro cantos do mundo onde se fala a língua de Camões. Os povos lusófonos completariam, desse modo, o trabalho de unificação da humanidade que iniciaram no final do século XIV.

A finalidade do movimento deve ser, não somente pensar as instituições políticas do mundo unificado de amanhã, mas também atuar, mediante ações educativas, no sentido de uma mudança geral de costumes e mentalidades, sem a qual as instituições políticas são condenadas à esterilidade. 
Sugiro, para esse fim, que se crie, com sede em Coimbra, uma associação internacional destinada a dirigir e incentivar esse movimento, e ponho-me, desde já, à disposição de seus futuros dirigentes.

Concluo, lembrando as sábias palavras de Montesquieu:

Se eu soubesse de algo que fosse útil a mim, mas prejudicial à minha família, eu o rejeitaria de meu espírito.

Se soubesse de algo útil à minha família, mas não à minha pátria, procuraria esquecê-lo.

Se soubesse de algo útil à minha pátria, mas prejudicial à Europa, ou então útil à Europa, mas prejudicial ao Gênero Humano, consideraria isto como um crime.

Fábio Konder Comparato

Doutor honoris causa da Universidade de Coimbra, Doutor em Direito da Universidade de Paris, Professor Titular aposentado da Faculdade de Direito da Universidade de São Paulo 